\title{
THE ADDITIONAL HETEROCHROMATIC CHROMOSOME AND ITS INFLUENCE ON SEX CHROMOSOME PAIRING IN RUMEX
}

\author{
J. ŻUK \\ Department of General Genetics, \\ Institute of Biochemistry and Biophysics, Warsaw, Poland
}

Received 7.iii.68

\section{INTRODUGTION}

PaIring between partner chromosomes is specific and depends on homology, while nonspecific pairing between nonhomologous regions is, in most cases, the result of heterochromatic fusion (Riley and Law, 1965; Riley and Chapman, 1957; Person, 1955). The introduction of a new, experimentallyinduced, heterochromatic chromosome into normal male plants of $R$. thyrsiflorus changes the pattern of sex chromosome pairing and cause conjugation between nonhomologous partners. It is assumed that this change of chromosome pairing is also due to heterochromatic fusion. Some observations concerning the heterochromatic state of the new chromosome and its effect on the phenotype are presented here.

\section{Material AND METhods}

Dry seeds of $R$. thyrsiflorus collected from a natural population were treated with diepoxybutane (DEB) solutions of 0.003 and 0.01 per cent. concentration for 2 hours at about $20^{\circ} \mathrm{C}$. Immediately after treatment the seeds were washed with water and sown in pots. Root tips were treated with 8-oxyquinoline before fixation in a 3 alcohol: acetic acid mixture, stored in a refrigerator and examined in aceto-orcein squash preparations. For investigation of meiotic chromosome pairing the alcoholic hydrochloric carmine method was used (Snow, 1963).

\section{Results}

R. thyrsiflorus is dioecious with chromosome constitution of $2 n=14=$ $\mathrm{XX}+12 \mathrm{~A}$ and $\delta 2 n=15=\mathrm{XY}_{1} \mathrm{Y}_{2}+12 \mathrm{~A}$. The mechanism of sex determination in $R$. thyrsiflorus is of the Drosophila type. In this species sex depends on the ratio of autosomes to the $\mathrm{X}$ chromosomes, $\mathrm{Y}$ chromosomes play no major role in sex determination. The $\mathrm{X}$ chromosomes are euchromatic. Both $\mathrm{Y}$ chromosomes are heterochromatic and late replicating. Heterochromatic segments are present also in two pairs of autosomes ( $j$ and $v, \dot{Z} u k$, 1967). The autosomes form six bivalents. In female plants two X chromosomes form a bivalent while, in male plants, a trivalent $\mathrm{Y}_{1}-\mathrm{X}-\mathrm{Y}_{2}$ is formed. The homologous segmens of the $\mathrm{X}$ ad $\mathrm{Y}$ chromosomes are very short and at diakinesis they associate end-to-end giving an long characteristic trivalent with the $\mathrm{X}$ in the middle (plate II, fig. 1).

Cytological observations were made in about 50 of the DEB-treated plants. Most of them had normal karyotypes but with small translocations in some instances. Most interesting were two female plants $2 n=\mathrm{XX}+12 \mathrm{~A}+\mathrm{S}$ 
(supernumerary) with three instead of two large metacentric chromosomes (plate I, fig. 1). In most cells all three chromosomes were equal in length but in some cases one of them seemed to be somewhat shorter (6.5 instead of $7 \mu$ long) but this difference is not significant. Several crosses between o $2 n=15=\mathrm{XX}+12 \mathrm{~A}+\mathrm{S}$ and $\delta 2 n=15=\mathrm{XY}_{1} \mathrm{Y}_{2}+12 \mathrm{~A}$ plants were performed in order to transfer the $\mathrm{S}$ chromosome to the male plants. In the progeny of 123 individuals cytologically investigated (table 1) only

TABLE 1

Progeny of crosses between plants 우 $2 n=15=\mathrm{XX}+12 \mathrm{~A}+\mathrm{S} \times ð 2 n=15=\mathrm{XY}_{1} \mathrm{Y}_{2}+12 \mathrm{~A}$

\begin{tabular}{|c|c|c|c|c|}
\hline \multirow[b]{2}{*}{$\begin{array}{l}\text { No. of } \\
\text { cross }\end{array}$} & \multicolumn{3}{|c|}{ Karyotypes } & \\
\hline & $14=X X+12 A$ & $\begin{array}{l}15=X X+12 A+S \\
15=X Y_{1} Y_{2}+12 A\end{array}$ & $16=X Y_{1} Y_{2}+12 A+S$ & Total \\
\hline 1 & 17 & 7 & - & 24 \\
\hline 2 & 3 & 6 & - & 9 \\
\hline 3 & 4 & 6 & - & 10 \\
\hline 4 & 49 & 28 & 3 & 80 \\
\hline Total & 73 & 47 & 3 & 123 \\
\hline
\end{tabular}

three plants with karyotype $2 n=16=\mathrm{XY}_{1} \mathrm{Y}_{2}+12 \mathrm{~A}+\mathrm{S}$ were found (plate I, fig. 2). These plants were male which indicates that the $\mathrm{S}$ chromosome plays no role in sex determination and it cannot be considered as an additional X chromosome. Observations of mitotic prophase in males and females revealed that this $\mathrm{S}$ chromosome is completely heterochromatic (plate I, figs. 3 and 4). Thus, it would appear that heterochromatisation of the new $\mathrm{S}$ chromosome is permanent and not physiological ( $c f$. Lyon effect).

TABLE 2

Number of large heterochromatic blocks in normal plants and those containing the $S$ chromosome

Karyotypes

$14=\mathrm{XX}+12 \mathrm{~A}$

$15=\mathrm{XX}+12 \mathrm{~A}+\mathrm{S}$

$15=\mathrm{XX}+12 \mathrm{~A}+\mathrm{S}$

$15=X Y_{1} Y_{2}+12 A$

$16=X Y_{1} Y_{2}+12 A+S$

$16=X Y_{1} Y_{2}+12 A+S$
Number of large heterochromatic blocks in cell

\begin{tabular}{rrrrr}
\hline 0 & 1 & 2 & 3 & $\begin{array}{c}\text { no. of } \\
\text { cells }\end{array}$ \\
100 & - & - & - & 100 \\
53 & 47 & - & - & 100 \\
43 & 57 & - & - & 100 \\
45 & 1 & 54 & - & 100 \\
63 & - & 37 & - & 100 \\
52 & 1 & 44 & 3 & 100
\end{tabular}

The heterochromatic state of $\mathrm{S}$ chromosomes was also confirmed by observation of the presence of large heterochromatic blocks in the interphase nuclei of male and female plants. As may be seen from the data of table 2 in interphase nuclei of normal female plants no big heterochromatic blocks are formed. In normal male plants there are two big heterochromatic blocks in more than 50 per cent. of interphase nuclei. In female plants with karyotype $2 n=15=\mathrm{XX}+12 \mathrm{~A}+\mathrm{S}$ one big heterochromatic block was observed in about 50 per cent. of cells. In male plants with karyotype $2 n=16=$ $\mathrm{XY}_{1} \mathrm{Y}_{2}+12 \mathrm{~A}+\mathrm{S}$ the number of blocks was the same as in normal male plants probably as a result of heterochromatin fusion between $\mathbf{S}$ and one or other 


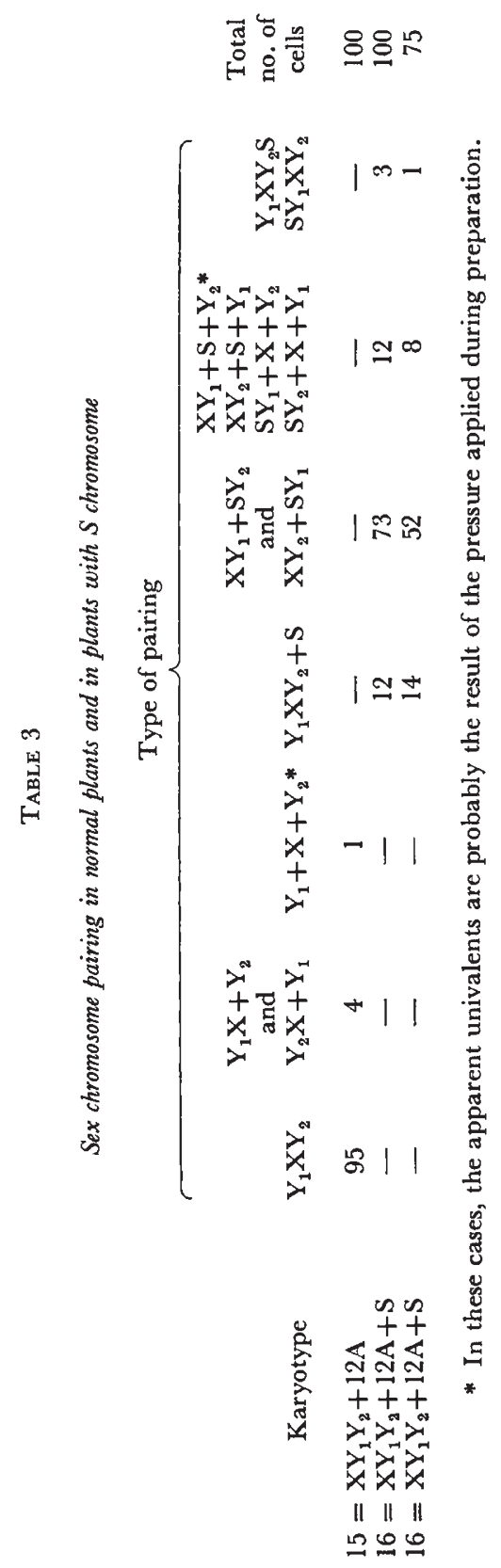


of the $\mathrm{Y}$ chromosomes. In some of the interphase nuclei of female plants, the whole $\mathrm{S}$ chromosome was in a highly condensed state (plate I, fig. 5). No such large heterochromatic knobs was observed in normal female plants without S chromosome (plate I, fig. 6).

The size and morphology of the $\mathrm{S}$ chromosome suggest that it could have arisen by nondisjunction of one of the $\mathrm{X}$ chromosomes. But the heterochromatic state of the new $\mathrm{S}$ chromosome rather suggests an origin from the fusion of heterochromatic segments of $j$ and $v$ autosomes. To elucidate this point meiotic chromosome pairing was examined. The mode of sex chromosome pairing in of $2 n=15=\mathrm{XY}_{1} \mathrm{Y}_{2}+12 \mathrm{~A}$ and $\pi \quad 2 n=16=$ $\mathrm{XY}_{1} \mathrm{Y}_{2}+12 \mathrm{~A}+\mathrm{S}$ plants is given in table 3 . The result of analysis were rather unexpected. In plants $2 n=16=\mathrm{XY}_{1} \mathrm{Y}_{2}+12 \mathrm{~A}+\mathrm{S}$ in about 80 per

TABLE 4

Progeny of cross between plants $q 2 n=14=\mathrm{XX}+12 \mathrm{~A}$ and ${ }^{\star} 2 n=16=\mathrm{XY}_{1} \mathrm{Y}_{2}+12 \mathrm{~A}+\mathrm{S}$ as determined from seedling

\begin{tabular}{|c|c|c|}
\hline \multicolumn{3}{|c|}{ Karyotypes } \\
\hline $14=\mathrm{XX}+12 \mathrm{~A}$ & $\begin{array}{l}15=\mathrm{XY}_{1} \mathrm{Y}_{2}+12 \mathrm{~A} \\
15=\mathrm{XX}+12 \mathrm{~A}+\mathrm{S} \\
15=\mathrm{XY}_{2}+12 \mathrm{~A}+\mathrm{S} \\
15=\mathrm{XX}+12 \mathrm{~A}+\mathrm{S}\end{array}$ & $16=X Y_{1} Y_{2}+12 A+S$ \\
\hline
\end{tabular}

20

39

Total

60

cent. of p.m.c.'s no sex trivalent was formed. Instead, eight bivalents were observed, six formed by autosomes and two by the sex $\left(X Y_{1} Y_{2}\right)$ and $S$ chromosomes (plate II, fig. 2). During late diakinesis the $\mathrm{X}$ and $\mathrm{Y}$ chromosomes are similar in size and practically indistinguishable from one another in this highly contracted state. So it is also impossible to distinguish different type of bivalents formed by $\mathrm{Y}_{1}, \mathrm{Y}_{2}, \mathrm{X}$ and $\mathrm{S}$ chromosomes. But theoretically four types of bivalents could be formed: $\mathrm{XY}_{1}, \mathrm{XY}_{2}, \mathrm{SY}_{1}$ and $\mathrm{SY} \mathrm{Y}_{2}$. It is assumed that $\mathrm{Y}_{1} \mathrm{Y}_{2}$ cannot be formed because of the lack of homology. From this it follows also that the formation of XS bivalent is improbable. In all types of bivalents conjugation was as a rule end-to-end.

In some p.m.c., besides the four types of bivalents described, other association between $\mathrm{S}$ and $\mathrm{X}, \mathrm{X}_{1}, \mathrm{Y}_{2}$ chromosomes were also found. The formation of a normal sex chromosome trivalent and a $\mathrm{S}$ univalent was quite frequent (plate II, fig. 3). In some p.m.c.'s more than one apparent univalent was observed but this was rather the result of the pressure applied on the cover slip as in the case for some p.m.c.'s of normal male plants (table 3). Occasionally also various associations of four were seen (plate II, fig. 4, 5). In some cases prereduction of XY and SY bivalents was observed in AI. Pre-anaphase movement of these bivalents is illustrated in fig. 6 of plate II. Such behaviour may be connected with the heterochromatic state of the $S$, $Y_{1}$ and $Y_{2}$ chromosomes and their end-to-end associations in bivalents.

Some observations were performed concerning the transmission of the new chromosome to the progeny as well as its effect on plant morphology. From the data of tables 1 and 4 it is evident that transmission of the $\mathrm{S}$ chromosome to the progeny is only about 50 per cent. on the female and about 65 per cent. on the male side. This can be explained by selective fertilisation, nonrandom degeneration of cells during meiosis in macro- 
sporogenesis or by the lower viability of zygotes with an additional $\mathrm{S}$ chromosome.

Observations concerning the influence of $\mathrm{S}$ chromosome on plant morphology revealed that individuals with the additional chromosome are about $10 \mathrm{~cm}$. shorter than the normal ones. The leaves of such plants are paler and somewhat curled. Fertility in male and female plants with the $\mathrm{S}$ chromosome is $10-30$ per cent. below normal.

\section{Discussion}

Two points require a more detailed discussion, namely, the origin of the supernumerary and the nature of its conjugation with a nonhomologous $Y$ chromosome. Two possible origins can be suggested. First, nondisjunction and subsequent heterochromatisation of the normal $\mathrm{X}$ chromosome and, second, breakage of certain autosomes followed by fusion of their heterochromatic segments. The size of the new chromosome supports the first possibility. But its heterochromatic state, the fact that $2 n=16=\mathrm{XY}_{1} \mathrm{Y}_{2}+$ $12 \mathrm{~A}+\mathrm{S}$ plants are male and the lack of pairing between $\mathrm{X}$ and $\mathrm{S}$ suggest rather an origin by fusion of autosomal herteochromatic segments.

McCleish (1953) reported the randon association of heterochromatic chromosome segments in Vicia during interphase. The same may be true also for Rumex. Dyer (1964) obtained some indications that euchromatin can be converted to heterochromatin as a result of translocation between hetero- and eu-chromatic segments. In such a case the contraction of translocated euchromatin can be affected by the proximity of heterochromatin. Taking into account these two observations, it is possible to imagine that the $\mathrm{S}$ chromosome could arise by fusion of the heterochromatic arms of the $j$ and $v$ chromosomes or by some combinations of both eu- and hetero-chromatic segments of the $R$. thyrsiflorus autosome set. The first step was induction of a few breakages by DEB treatment followed by translocations and fusion of broken ends.

There are also some data on chromosome pairing during meiosis in haploid plants which have a bearing on the nonhomologous conjugation between the S and Y chromosomes. According to Levan (1942) nonhomologous pairing in haploid rye seems to start at the heterochromatic segments. Person (1955) reported e-e (end-to-end) and s-s (side-by-side) association of chromosome during meiosis in haploid Triticum aestivum. He suggested that homology is not a factor in the formation of e-e associations. Riley and Chapman (1957) also observed two main types of univalent associations (e-e and s-s) in polyploids and haploids of Aegilops Triticum. They suggested that all types of univalent associations were due to heterochromatin fusion. Southern (1967) described nonhomologous associations in Metrioptera brachyptera as a consequence of a persistent heterochromatic association between large heterochromatic blocks.

It is possible that the e-e association observed in Rumex between nonhomologous $\mathrm{S}$ and $\mathrm{Y}$ chromosomes is also due to heterochromatic fusion. This conclusion is supported by the observation of interphase nuclei in plants with additional $\mathrm{S}$ chromosome. The presence of two big heterochromatic blocks in plants with $2 n=16=\mathrm{XY}_{1}+\mathrm{Y}_{2}+12 \mathrm{~A}+\mathrm{S}$ instead of three formed by $S, Y_{1}$ and $Y_{2}$ chromosomes indicates $S Y$ fusion to form one common heterochromatic block. This fusion is maintained as the cells go into meiosis, 
and in effect gives an e-e association between $\mathrm{S}$ and one of the $\mathrm{Y}$ chromosomes.

It is interesting why $\mathrm{Y}_{1}$ and $\mathrm{Y}_{2}$ chromosomes do not form one common heterochromatic block in interphasel nuclei of normal male plants. There is good reason to assume that a special mechanism develops during the evolution of dioecious $R$. thyrsiforus to prevent the fusion of heterochromatic $\mathrm{Y}$ chromosomes. This mechanism probably eliminates $Y_{1} Y_{2}$ associations and thus facilitates the regular behaviour of the sex chromosome mechanism.

\section{Summary}

1. A new $\mathrm{S}$ chromosome was induced in diploid plants of $R$. thyrsiflorus by DEB treatment.

2. The $\mathrm{S}$ resembled the $\mathrm{X}$ in size and morphology but differed in being fully heterochromatic and it played no role in sex determination.

3. At meiosis in male plants the $\mathrm{S}$ usually formed a bivalent with one of the $\mathrm{Y}$ chromosomes.

4. The $\mathrm{S}$ chromosome could have arisen by nondisjunction of the $\mathrm{X}$ chromosome or by fusion of heterochromatic segments of autosomes. The second hypothesis seems to be more plausible.

5. Nonhomologous associations between $\mathrm{S}$ and $\mathrm{Y}$ chromosomes may depend on the heterochromatic state of both these chromosomes.

Acknowledgments.-I would like to express my sincere thanks to Dr K. R. Lewis and Professor W. Gajewski for critical reading of manuscript.

\section{REFERENGES}

DYER, A. F. 1964. Heterochromatin in American and Japanese Species of Trillium. II. The behaviour of H-segments. Cytologia, 29, 2, 171-189.

LEVAN, A. 1942. Studies on the meiotic mechanism of haploid rye. Hereditas, 28,177-211. MCLEISH, J. 1953. The action of maleic hydrazide in Vicia. Supplement to Heredity, 6, 125-147. PERSON, c. 1955. An analitical study of chromosome behaviour in a wheat haploid. Can. $\mathcal{J}$. Bot., 33, 11-30.

RILEY, R., AND CHAPMAN, v. 1957a. Haploids and polyhaploids in Aegilops and Triticum. Heredity, 11, 195-207.

RILEY, R., AND LAW, C. N. 1965. Genetic variation in chromosome pairing. Advances in Genetics, 13, 57-114.

SNOw, R. 1963. Alcoholic hydrochloric acid-carmine as a stain for chromosome in squash preparation. Stain Technology, 38, 9-13.

SOUTHERN, D. I. 1967. Pseudo-multiple formation as a consequence of prolonged nonhomologous chromosome association in Metrioptera Brachyptera. Chromosoma (Berl.), $21,272-284$.

zuk, J. 1963. An investigation on polyploidy and sex determination within the Genus Rumex. Acta Societatis Botanicorum Poloniae, 32, 5-67.

zUK J. 1967. Autoradiographic Studies in Rumex with Special Reference to Sex Chromosomes. The Second Oxford Chromosome Conference, Sept. 1967 in press. 

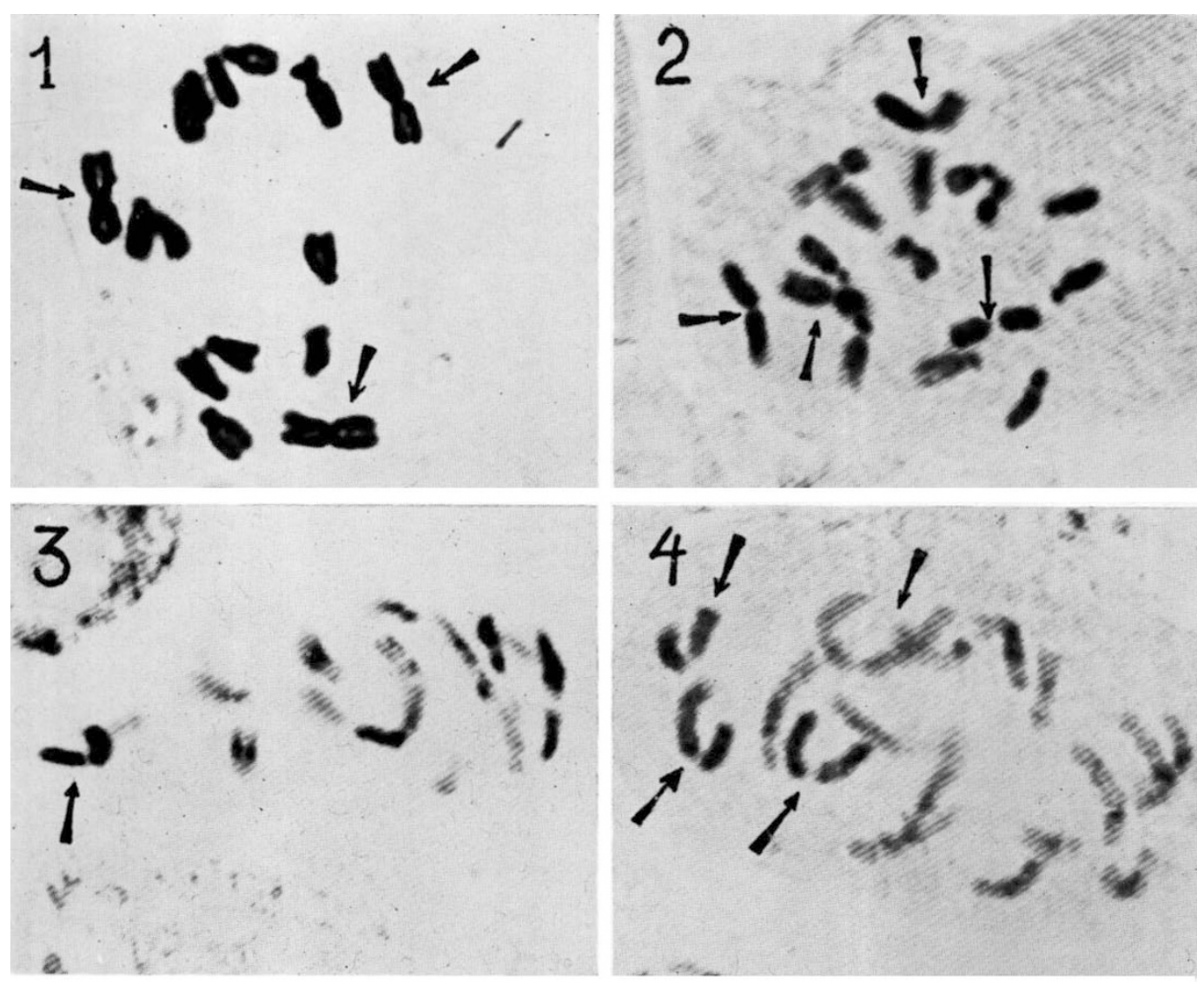

5
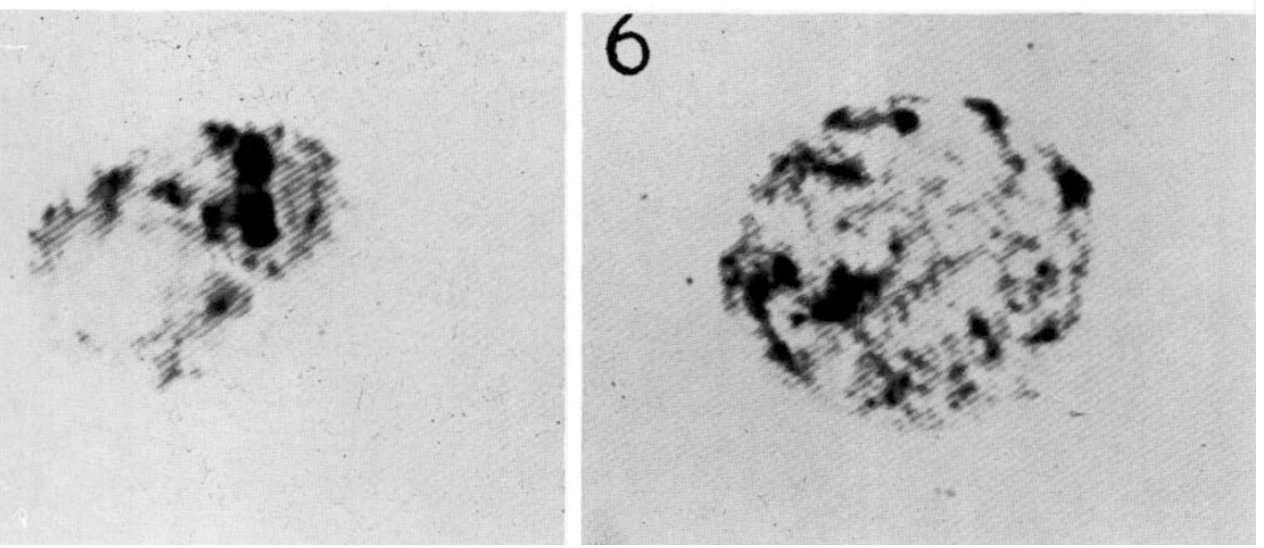

Metaphase, prophase and interphase nuclei of plants with the additional S chromosome, and interphase nuclei of normale female plant. $\times 2000$.

Fig. 1.-Female plant $2 n=15=\mathrm{XX}+12 \mathrm{~A}+\mathrm{S}$. Arrows indicate two $\mathrm{X}$ and $\mathrm{S}$ chromosomes.

Fig. 2.-Male plant $2 n=16=\mathrm{XY}_{1} \mathrm{Y}_{2}+12 \mathrm{~A}+\mathrm{S}$. Arrows indicate $\mathrm{S}$, two $\mathrm{Y}$ chromosomes and an $\mathrm{X}$ chromosome.

FIG. 3.-Female plant $2 n=15=\mathrm{XX}+12 \mathrm{~A}+\mathrm{S}$. Arrow indicates positively heteropycnotic $\mathrm{S}$ chromosome.

FIG. 4.-Male plant $2 n=16=\mathrm{XY}_{1} \mathrm{Y}_{2}+12 \mathrm{~A}+\mathrm{S}$. Arrows indicate positively heteropycnotic $S Y_{1} Y_{2}$ chromosomes and an euchromatic $X$ chromosome.

Fig. 5.-Female plant $2 n=15=\mathrm{XX}+12 \mathrm{~A}+\mathrm{S}$. Note heterochromatic, highly condensed, $\mathrm{S}$ chromosome.

Fig. 6. - Female plant $2 n=14=\mathrm{XX}+12 \mathrm{~A}$. Note lack of big heterochromatic knob. 

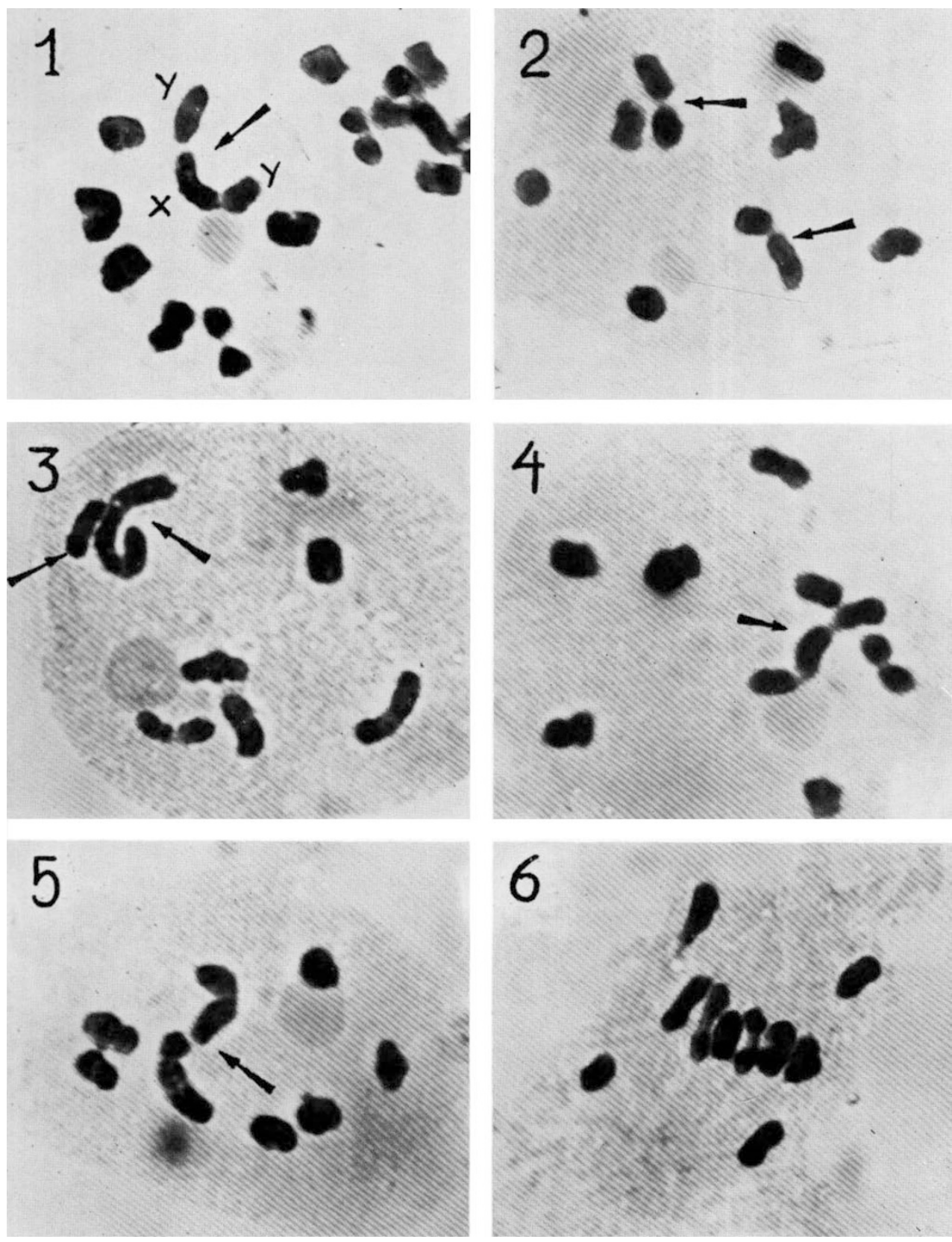

Chromosome association at meiosis in normal male plants and in those with the additional $\mathrm{S}$ chromosome. $\times 2000$.

FIG. 1.-Diakinesis $2 n=15=\mathrm{XY}_{1} \mathrm{Y}_{2}+12 \mathrm{~A}$. Arrow indicates trivalent formed by sex chromosomes $\left(\mathrm{Y}_{1} \mathrm{XY}_{2}\right)$.

FIG. 2.-Diakinesis in plant with karyotype $2 n=16=\mathrm{XY}_{1} \mathrm{Y}_{2}+12 \mathrm{~A}+\mathrm{S}$. Arrows indicate bivalents formed by $\mathrm{X}, \mathrm{S}, \mathrm{Y}_{1}, \mathrm{Y}_{2}$ chromosomes. Note end-to-end association in these bivalents.

FIG. 3.-Diakinesis in plant with karyotype $2 n=16=\mathrm{XY}_{1}+12 \mathrm{~A}+\mathrm{S}$. Arrows indicate trivalent and univalent formed by $\mathrm{X}, \mathrm{S}, \mathrm{Y}_{1}, \mathrm{Y}_{2}$ chromosomes.

FIG. 4.-Diakinesis in plant with karyotype $2 n=16=\mathrm{XY}_{1} \mathrm{Y}_{2}+12 \mathrm{~A}+\mathrm{S}$. Arrow indicates tetravalent formed by $\mathrm{X}, \mathrm{S}, \mathrm{Y}_{1}, \mathrm{Y}_{2}$ chromosomes. Note side-to-end association between two chromosomes in tetravalent.

FIG. 5.-Diakinesis in plant with karyotype $2 n=16=\mathrm{XY}_{1} \mathrm{Y}_{2}+12 \mathrm{~A}+\mathrm{S}$. Arrow indicates tetravalent formed by end-to-end association of $\mathrm{X}, \mathrm{S}, \mathrm{Y}_{1}, \mathrm{Y}_{2}$ chromosomes, such association produced a linear chain.

Fig. 6.-Late metaphase in p.m.c. of plant with karyotype $2 n=16=\mathrm{XY}_{1} \mathrm{Y}_{2}+12 \mathrm{~A}+\mathrm{S}$. Note prereduction of bivalents formed by $\mathrm{X}, \mathrm{S}, \mathrm{Y}_{1}, \mathrm{Y}_{2}$ chromosomes. 